responsible in any absolute sense. "Freedom is a relationship between the different elements of the self," and the difference between an act that is free and one that is not free is not the difference between an act that is indetermined and an act that is determined, but the difference between an act that is the result of an unsystematised determinism and one that is the result of systematised determinism. The theory of indeterminism, he concludes, has little bearing on the theory of the will, the connection being merely due to an ancient confusion between indeterminism and freedom, so that in psychological as in physical science it is reasonable to accept determinism.

The subject of the will no longer possesses the acute importance which it had for all in the days when psychology was ruled by metaphysicotheological conceptions. But it still has its interest, and not least to the alienist, who from time to time finds the ancient metaphysicotheological conceptions flaunted before his eyes. The present volume will be found helpful and suggestive by those who wish to attain a clear view of the present attitude of thinkers towards the subject-all the more so, perhaps, because it is written without thought of medico-legal applications. The style is throughout simple and pleasant.

Havelock Ellis.

\title{
Manuel de Psychiatrie. By J. Rogues DE Fursac. Paris : Alcan, 1903. Pp. 314, 8vo.
}

To write a handbook of psychiatry nowadays is a very much more serious task than it was thirty years ago. The wide extension of the outlying provinces of morbid psychology, the need of taking into account the methods of normal psychology, and the growing tendency to regard abnormal mental conditions as the outcome of general somatic conditions, alone combine to render a brief magisterial discussion of the vast field so complex a task that even the youngest and most omniscient alienist may well feel appalled. There are, however, still two ways in which even a man who is not endowed with a special genius for this task may yet hope to accomplish it with fairly interesting results. That is, he may either after long experience summarise the results of his own personal observation and knowledge in such shape as may seem best to him ; or else, at an earlier stage in his career, he may seek out the best that is known and thought in his time, and rely on the masters he has chosen to follow rather than on his own experience. The first method has the disadvantage that it may tell us nothing about the general tendency of contemporary psychiatry, but on the other hand it cannot fail to contribute instructive and useful observations; the second method has the disadvantage that it may yield nothing of original value, but on the other hand it may furnish a valuable indication of the contemporary trend of psychiatry.

The present volume evidently belongs to the second class mentioned. The name of Dr. Rogues de Fursac seems unfamiliar, but he easily allows us to place him. He is a pupil of Joffroy (to whom the book is

XLIX. 
dedicated), and he adopts almost without modification the classification of Kraepelin, to whom he frequently refers with admiration. Throughout he presents us with the combined teaching of these two masters.

The book is divided into a shorter part dealing with general psychiatry, and a longer part devoted to special psychiatry. The first part discusses etiology, general symptomatology, and general methods of treatment. In the second part the various forms of insanity are discussed, Kraepelin being followed in all main outlines. The chapter on general paralysis may be referred to as showing the author at his best ; the present position of knowledge and opinion in regard to this subject is set forth in a comprehensive, methodical, and precise manner, and a judicious attitude is taken on the much-debated question of etiology; with Joffroy, Näcke, etc., the author emphasises the importance of neuropathic (not psychopathic) heredity as a predisposing cause of the disease, and among the exciting causes syphilis is regarded as "the most important and perhaps as essential." While thus admitting the great importance of syphilis in the etiology, the author concludes that we are not entitled to affirm (with Fournier and others) that general paralysis is a syphilitic disease. He suggests that it may perhaps constitute a syndroma which various causes may suffice to evoke, and that possibly we ought to speak of general paralyses rather than of a single general paralysis. As might be anticipated, dementia præcox is dealt with fully, under three forms : simple, katatonic, with delirium. Two chapters are devoted to alcoholism and two to the auto-intoxications, including myxœedema and cretinism. There is a (somewhat perfunctory) discussion of sexual perversions, in which inversion is regarded as always congenital, and also of obsessions, both under the head of constitutional psychopathics; while chapters are devoted to epilepsy and hysteria.

It will be seen that the author covers his large field in a fairly comprehensive manner, though at places the treatment is thin. He shows a fairly wide acquaintance with German literature, but, while anxious to do justice all round, his direct knowledge of English, American, and Italian authors is evidently very small ; Darwin's name is Gallicised into "Darvin."

Havelock Ellis.

Prison Hospital Nursing: a Manual of First Aid and Nursing for the Prison Hospital Staff. By Herbert Smalley, M.D., Medical Inspector of Prisons. Published by authority. London, 1902. 8 vo, pp. 365 .

This is a notable book, marking as it does a new era in prison management. The frank recognition of scientific principles in the treatment of criminals reassures us. It is well known that there does exist a band of able workers in this department of State administration, of whom Dr. David Nicolson has long been a pioneer; but the service has been benumbed by obsolete ideas in high places, and it is only of late years that reformation of methods has been in the air. We 